\title{
Self-citations as strategic response to the use of metrics for career decisions
}

\author{
Marco Seeber $^{\mathrm{a}, *}$, Mattia Cattaneo ${ }^{\mathrm{b}}$, Michele Meoli $^{\mathrm{b}}$, Paolo Malighetti ${ }^{\mathrm{b}}$ \\ a Department of Sociology, Ghent University, Korte Meer 3, 9000 Ghent, Belgium \\ ${ }^{\mathrm{b}}$ Department of Engineering, University of Bergamo, Via Pasubio 7b, 24044 Dalmine, BG, Italy
}

A R T I C L E I N F O

\section{Keywords:}

Self-citations

Post-production misconducts

Incentives in science

Strategic scientists

Sociology of science

Economics of science

\begin{abstract}
A B S T R A C T
There is limited knowledge on the extent to which scientists may strategically respond to metrics by adopting questionable practices, namely practices that challenge the scientific ethos, and the individual and contextual factors that affect their likelihood. This article aims to fill these gaps by studying the opportunistic use of selfcitations, i.e. citations of one's own work to boost metric scores. Based on sociological and economic literature exploring the factors driving scientists' behaviour, we develop hypotheses on the predictors of strategic increase in self-citations. We test the hypotheses in the Italian Higher Education system, where promotion to professorial positions is regulated by a national habilitation procedure that considers the number of publications and citations received. The sample includes 886 scientists from four of science's main disciplinary sectors, employs different metrics approaches, and covers an observation period beginning in 2002 and ending in 2014. We find that the introduction of a regulation that links the possibility of career advancement to the number of citations received is related to a strong and significant increase in self-citations among scientists who can benefit the most from increasing citations, namely assistant professors, associate professors and relatively less cited scientists, and in particular among social scientists. Our findings suggest that while metrics are introduced to spur virtuous behaviours, when not properly designed they favour the usage of questionable practices.
\end{abstract}

\section{Introduction}

The practice of allocating resources and linking career advancement to research productivity is intended to break the old-boys network and promote meritocracy in academia. Yet in recent years concern has grown over the downsides of the resulting pressure to publish. Studies have shown that the 'publish or perish' culture and the use of metrics for research evaluation can have several detrimental effects, like the promotion of strategic game-playing and the decline of shared information (Anderson et al., 2007), a decrease in creativity (Azoulay et al., 2011; Heinze et al., 2009), an increase in plagiarism (Honig and Bedi, 2012), a surge in the production of redundant publications (Jefferson 1998), fads (Van Dalen and Klamer, 2005) and elitist research topics that are detached from practical and societal concerns (De Rond and Miller, 2005); they also discourage non-paradigmatic or atheoretical research, and favour ex-post hypothesizing (Miller, 2007), inflate the number of submissions (Franzoni et al., 2011), reduce the appearance of negative results (Fanelli, 2012), and promote the emergence of predatory journals (Xia et al., 2015).

The traditional belief that malpractice and misbehaviour are due to scientists who are not sufficiently socialized into the norms of science, e.g. junior researchers, is challenged by survey results suggesting that malpractice is rather common (Bedeian et al., 2010; Martinson et al., 2005) and retractions related to scientific misconduct is growing (Steen, 2010; Fang et al., 2012). Some scholars argue that due to academic competition and the use of performance indicators, an increasing number of scientists may be changing the conception of what constitutes appropriate research behaviour (Martin, 2013) by engaging in questionable practices to the point that they become embedded in the professional academic culture (Edwards and Roy, 2017).

However, despite evidence on the unintended effects of the pressure to publish, it is not yet clear the extent to which scientists adopt questionable practices as a strategic response to metrics (Fang et al., 2012). Moreover, we have little knowledge of what individual and contextual factors affect the likelihood of such behaviours among individual scientists (de Rijcke et al., 2016), and whether there are any disciplinary variations or not.

This article addresses these gaps by studying the behaviour of Italian academics in response to the introduction of a national habilitation procedure that regulates the promotion to professorial positions. While metrics have been employed for institutional evaluation and to inform decisions on individual career paths, this procedure directly links the possibility to become an associate professor and a full professor to the number of publications and citations (Marini, 2016). Hence, doing

\footnotetext{
* Corresponding author.

E-mail addresses: marco.seeber@ugent.be, seeber.marco@gmail.com (M. Seeber).
} 
well according to the metrics is a pre-condition for moving up the academic career ladder. In particular we study the use of self-citations, i.e. citations to one's own work, as a shortcut to boost metric scores. We focus on the practice of inflating self-citations, for they represent a typology of the emerging 'post-production misconducts' aimed at enhancing a publication's impact; while these misconducts do not generate false results, they nevertheless erode the credibility of the publication system (Biagioli, 2016). Moreover, inflating self-citations is at odds with the norm of disinterestedness that is central to the ethos of science (Merton, 1973). As such, opportunistic self-citations can signal that the norms of the scientific community are not effectively guarded, which is possibly conducive to increasing the number and severity of infringements. ${ }^{1}$ Finally, self-citations can be exploited in a rather short period of time, by adding citations to the articles in the pipeline meaning that an increase in self-citations can be easily detected. Therefore, self-citations represent a fast and visible indication on the extent to which scientists can opportunistically respond to the use of citations to drive career decisions, not to mention their role as a precious 'canary in a coal mine'. ${ }^{2}$

We build on sociological and economic studies of science to develop hypotheses on the factors that drive scientists to increase self-citations in response to the introduction of metrics-based career decisionmaking. We test the hypotheses considering the scientific production of 886 scientists from four disciplinary sectors from science's main research areas, which employed different metrics approaches, within an observation period that began in 2002 and ended in 2014.

In Section 2 we review the literature on the drivers of scientists' behaviour, and develop hypotheses on the adoption of questionable practices, namely increasing self-citations in response to metrics-based habilitation procedures. In Section 3 we present the data and method, while the empirical analysis is presented in Section 4. In the final section we discuss the article's main findings, the theoretical and policy implications, and advance proposals to counteract some of the potentially unintended effects of using of metrics.

\section{Strategic responses to metrics}

\subsection{Quantitative indicators for research evaluation}

In recent decades, quantitative indicators have proliferated and are widely used to assess scientific output, to drive the allocation of funds, and for the hiring and promotion of staff (Miller et al., 2005; Van Fleet et al., 2000; Harzing, 2010; Lissoni et al., 2011; de Rijcke et al., 2016). In parallel to their diffusion, a debate emerged regarding their conceptual and empirical validity as well as their unintended effects (MacRoberts and MacRoberts 1989; Garfield, 2003; Costas and Bordons, 2007). The use of indicators is based on the assumption that publications and the citations received are proxies of a scientist' contribution to the advancement of science (Merton, 1988; Moed, 2005; Haustein and Larivière, 2015). A crucial issue, therefore, is whether these indicators are reliable proxies or not.

In the case of publications, scientific journals must closely assess whether an article merits publishing, as the selection of low quality articles would endanger their reputation. On the other hand scholars have criticized the use of a journal impact factor as a proxy for the quality of articles, because the correlation between a journal impact factor and the citations received by an individual article is very low

\footnotetext{
${ }^{1}$ Such a mechanism is central in the "broken windows theory", which states that when people observe that others violate a certain norm or rule, they are more likely to violate other norms or rules, which causes violations to spread (Wilson and Kelling, 1982; Keizer et al., 2008).

${ }^{2}$ The expression describes an item that serves as an early indicator for a coming greater danger. It alludes to the use of caged canaries that miners carried into mines, and if dangerous gases collected, the canary was killed, thus warning the miners to exit immediately.
}

(Lozano et al., 2012).

For citations, scientists judge whether a published contribution is useful and necessary to be cited; for self-citations, an author assesses whether her/his past works were relevant when citing the article. In the case of citations and self-citations, there are slight gains or losses depending on whether authors are truthful or not. In fact, despite most scholars believing that citation counts are a poor representation of scientific contribution (Saha et al., 2003; Aksnes and Rip, 2009), at the article level there is evidence of a positive correlation between citation rates and qualitative judgement by peers (Cole and Cole, 1974; Zuckerman, 1987; Aksnes, 2006).

However, employing quantitative indicators for allocating resources or making decisions on careers enhances the risk that they become unreliable. In the case of publications, for instance, predatory journals, which do not have a reputation to protect and exchange publications for money, have emerged. In case of citations, the likelihood of a deceptive citation arguably grows with the proximity between the citing and the cited authors, as they can more easily collude and produce socalled citation rings. In the case of self-citations, the citing and cited authors are the same person, and so the risk that citations are aimed to game the system of indicators is even higher. Despite such limitations, there is no consensus on whether self-citations should be excluded for the sake of research evaluation, and only recently have some experts explicitly suggested their removal (Wouters et al., 2015).

\subsection{Strategic responses to metrics}

The response of scientists to metrics arguably depends on their motivations for action.

Classical sociological accounts depicted scientists' behaviour as being driven by the enjoyment derived from solving 'puzzles' as well as by the recognition from peers for achieving a discovery (Eiduson, 1962; Hagstrom, 1965). The scientists' social context was perceived as being dominated by an ethos of science - characterized by prescriptions of communalism, universalism, disinterestedness and organized scepticism (Merton, 1973; Hagstrom 1974; Zuckerman, 1977). Overall, scientists' motivations and the normative environment contributed to the efficiency of the scientific enterprise. Post-World War II research policies in Western countries developed under similar beliefs that scientists, left free to pursue their curiosity, would naturally provide the knowledge that a nation needed (Bush, 1945).

While sharing the importance of curiosity and peers' recognition, since the early nineties economists have argued that scientists are also interested in more mundane returns, namely money, and that their behaviour is not merely driven by ethical concerns, but that they are strategic in pursuing their goals (Levin and Stephan, 1991; Stephan, 1996). In a similar period, research policies have increasingly aimed to increase efficiency and performance through competition and the assessment of results (Auranen and Nieminen, 2010). Therefore, at least implicitly, policies have also experienced a similar shift in their assumptions about what drives scientists' behaviours, e.g. assuming that they are not necessarily interested in their own job and must therefore be spurred via incentives and controls.

Different perspectives on the nature of scientists lead to different interpretations and expectations on the adoption of questionable practices. Consistently with a Mertonian view of an ethical and disinterested scientist, early studies tended to blame the individual. Offenders were described as a few black sheep with peculiar psychological profiles, affected by anomie or alienation (Anderson et al., 1994; Hackett 1994). Adopting a more strategic perspective, subsequent studies paid attention to systemic, undesirable behaviours induced by an improper system of incentives (Stephan, 2012). Franzoni et al. (2011), 
for instance, found that the number of submissions to Science increased significantly in countries that introduced monetary incentives for publications, but the rate of acceptance decreased, so that in turn the effect was only to overload the review process. Practices that are counterproductive or indifferent in terms of achieving priority in a discovery are often adopted because they are valuable tools for increasing a scientist's metric scores. For instance, 'cutting' a scientific result into many works is profitable in terms of the number of articles and citations received, compared to presenting them in one work (Bornmann and Daniel, 2007), publication strategies become less selective and more specialized in order to maximise scores in bibliometric indicators (Costas and Bordons, 2007; Leahey, 2007).

This empirical evidence suggests that the use of citations for driving decisions on careers will affect the behaviour of a (strategic) scientist. Hence, we formulate the hypothesis that:

Hypothesis 1. Scientists that need to climb the career ladder - i.e. assistant and associate professors - will respond to the use of citations to guide career decisions by increasing the number of self-citations.

Moreover, since the gain from increasing citations is particularly strong for scientists that are cited less frequently - as they will need to reach their peers - therefore we expect that:

Hypothesis 2. Scientists that are cited less frequently than their peers of the same rank and discipline are more likely to respond to the use of citations to guide career decisions by increasing their number of selfcitations.

The social context in which scientists are embedded can also affect scientists' responses. In particular, Whitley (2007) argued that social sciences and humanities are more prone to imitate research practices and norms of dominant fields because they display a less cohesive social structure and, as a consequence, the impact of evaluation systems will be stronger. Some studies back this argument. Hammarfelt and de Rijcke (2015) recently observed an increase in the number of journal articles written in English - the typical output of science, technology, engineering and mathematics - among scientists in the humanities, and Aagaard et al. (2015) found that the Norwegian national indicator for research evaluation is used more frequently at the individual level and is more important for judging scholarly status in the humanities. Reale and Seeber (2011) found that the introduction of a research assessment exercise in Italy had a stronger effect on the research practices of management scientists, than scientists in physics and biomedical science, since the latter were already accustomed to considering the number of articles appearing in international journals and citations as proxies for scientific value. Hence, we formulate the hypothesis that:

Hypothesis 3. Scientists from social science disciplines are more likely to respond to the use of citations to guide career decisions by increasing their number of self-citations, when compared to scientists from natural science and medical disciplines.

\section{Data and methods}

\subsection{Context of analysis}

We test the hypotheses in the context of Italian higher education.

This system is predominantly public, with almost $95 \%$ of academics employed by public universities ${ }^{3}$ that are funded by the public's purse (ETER, 2014). In the past, Italian higher education was governed by a centralized bureaucracy that exerted procedural control through laws and regulations, and by powerful chairs, which had the power to make decisions concerning academic issues and individual careers (Clark

\footnotetext{
${ }^{3} 46,314$ full time academics employed in public universities on total 48,881-year 2016 (Cineca - http://cercauniversita.cineca.it/php5/docenti/cerca.php).
}

1983; Pezzoni et al., 2012). From the mid-nineties, reforms loosely inspired by the principles of New Public Management aimed to change the governance of the system, from a steering "by law and regulation" approach to a steering "by objective" approach, in which resource allocation is driven by performance and universities gain more managerial autonomy. Accordingly, decisions over careers moved from national to university-selected disciplinary committees. However, the devolution of powers to the universities was not accompanied by a strong enough system of accountability, and the distribution of resources has remained weakly competitive (Reale and Seeber, 2011). In this context, the number of citations and publications were not important criteria for promotion, and the recruitment procedures have been increasingly criticized due to the alleged lack of meritocracy, the high level of localism, and cases of cronyism and nepotism (Morano Foadi, 2006; Durante et al., 2011). ${ }^{4}$

In order to address such criticisms, in late 2010 the government introduced a national habilitation procedure regulating access to professorial positions (Donina et al., 2015). Accordingly, disciplinary committees can award the associate or full professor habilitation only if the candidate meets at least two out of the three thresholds of productivity. Two metric approaches could be adopted. In the so-called bibliometric approach the candidate should outperform the median productivity of the current body of associate or full professors in at least two out of three productivity indicators: i) number of publications, ii) number of citations received and iii) Hirsch index. ${ }^{5,6}$ In the so-called non-bibliometric approach the number of citations are not considered as a criterion, instead each committee sets distinct thresholds of productivity in terms of a minimum number of publications in pre-defined i) 'first class' and ii) 'second class' journals, as well as iii) number of books.

In turn, the Italian habilitation procedure presents some features that allow an exploration of strategic responses to metrics and the adoption of questionable practices. First, while metrics have traditionally been used to support career decisions, the habilitation procedure directly impacts the possibility of career advancement. Second, the habilitation is applied at the system level and to all disciplines. Third, the habilitation allows one to explore the effects of different metric systems.

\subsection{Sample}

The construction of the sample was driven by empirical and theoretical considerations.

\subsubsection{Level}

From a disciplinary perspective, the Italian Higher Education system is organized in 367 disciplinary sectors, nested in 188 recruitment sectors, 88 macro-sectors and 14 macro-areas. The 'recruitment sector' is the level at which metrics are defined and habilitation awarded, and therefore we focused on identifying an appropriate selection (from now onward 'discipline').

\subsubsection{Size}

We selected disciplines with a size that is typical of the recruitment sectors in the Italian Higher Education system (median of 241 members), while avoiding disciplines that are too small as they could be

\footnotetext{
${ }^{4}$ In 2012 , a survey of 4700 assistant professors found that career progression is regarded as solely based on merit only by $0.8 \%$ of the respondents, $18.4 \%$ considered it a mix of merit and seniority, $19.5 \%$ considered the system based on established hierarchies and personal relationships and $36.8 \%$ did not identify any criteria adopted (Monteleone and Torrisi, 2012)

5 The definition of the Hirsch index - of $\mathrm{H}$ index - is that a scholar with an index of $\mathrm{h}$ has published $\mathrm{h}$ papers each of which has been cited in other papers at least $\mathrm{h}$ times (Hirsch, 2005)

${ }^{6}$ The individual productivity scores are normalized by taking into consideration the number of years from the first publication.
} 
Table 1

Characteristics of the recruitment sectors.

\begin{tabular}{|c|c|c|c|c|c|}
\hline Recruitment Sector & Science' Area & Metric approach & universities & scientists (2014) & publications (2002-2014) \\
\hline Economic and Managerial Engineering & Social Science & Bibliometric & 36 & 221 & 3429 \\
\hline Genetics & Natural Science & Bibliometric & 42 & 260 & 5481 \\
\hline Psychiatry & Medicine & Bibliometric & 38 & 258 & 10,271 \\
\hline \multirow[t]{2}{*}{ Applied Economics } & Social Science & Non-bibliometric & 53 & 147 & 1384 \\
\hline & & & 169 & 886 & 20,565 \\
\hline
\end{tabular}

problematic for the sake of statistical analysis. Further, we included the entire population of scientists from a discipline in order to avoid the possibility of a selection bias.

\subsubsection{Data availability}

We selected disciplines for which the majority of the research outcome is covered by publication databases; hence, we excluded disciplines in arts and humanities, as the research production is predominantly in Italian and consists of books.

\subsubsection{Disciplinary coverage}

We sampled four disciplines from sciences' major research areas, namely Genetics (natural sciences), Psychiatry (medicine), Economic and Managerial Engineering and Applied Economics (social sciences).

\subsubsection{Metric approaches}

Applied Economics adopts a non-bibliometric approach whereas the other three disciplines adopt a bibliometric approach. The choice of the two sectors in the social sciences aimed to recreate a (quasi) experimental design, where an experimental group (Economic and Managerial Engineering) is subjected to the experimental treatment (the use of citations as a metric) and is compared with a control group (Applied Economics) that does not receive the treatment (citations are not used as a metric). Quasi-experiments are subject to concern regarding their internal validity when the treatment and control groups are not comparable at baseline. Hence, we chose these two sectors for they resemble each other in several instances. In terms of composition, they both include, to a very large extent, scientists with a background in Economics. In terms of publication behaviour, scientists from the two disciplines: i) are similarly productive: average of articles per year 2.24 in Applied Economics vs. 2.44 in Economic and Managerial Engineering; ii) they publish in very similar outlets: only $13 \%$ of the articles in Applied Economics are published in journals where scientists from Economic and Managerial Engineering do not publish, and 37\% when reversed; iii) the level of collaboration is somewhat similar: the number of coauthors per article is 2.73 in Applied Economics versus 3.13 in Economic and Managerial Engineering; iv) until the introduction of the habilitation procedure in 2010 , the number of self-citations per author-article was also very similar: 0.62 in Applied Economics vs. 0.60 in Economic and Managerial Engineering. ${ }^{7}$

We retrieved information on publications, citations, affiliations, and the career evolution of the entire population of scientists from the four disciplines, for a total of 886 academics, from 2002 to $2014 .^{8}$ Data on publications and citations were retrieved on August 2016 from the

\footnotetext{
${ }^{7}$ No legal restriction exists on the number of disciplines a scientist can apply for habilitation, yet a scientist can be affiliated with only one discipline and in practice the overwhelming majority of scientists' careers occur within one single discipline. None of the scientists in our sample has been affiliated to both disciplines in the considered period.

${ }^{8}$ We excluded year 2015, since on the date of the extraction, the information was not yet complete. For each scientist we excluded years in which the person was not affiliated with the recruitment sector.
}

Scopus database. ${ }^{9,10}$ Information on scientists' careers and affiliations were retrieved from the Cineca database. ${ }^{11}$

Table 1 presents the main characteristics of the selected recruitment sectors. $^{12}$

In the following paragraphs, we first describe the dependent variable. Next, we introduce the variables that predict the propensity to self-cite. Finally, we describe our main independent variables, which predict the increase of self-citations in response to the use of citations to guide career decisions.

\subsection{Dependent variable}

The dependent variable is a scientist's average number of self-citations per article published in year i. ${ }^{13}$ Self-citations are defined as the citations to the author(s) previous works included in the reference list of the articles published in year $i$.

It is important to remark that an increase in self-citations might well indicate that the scientist's work tends to be related to her/hisprevious work more so than in the past. However, a rapid increase in self-citations corresponding to the introduction of the habilitation procedure is likely indicative of a strategic use of self-citations rather than a narrowing research focus, because some years are arguably necessary to change one's way of doing research.

\subsection{Variables predicting the number of self-citations}

Some 'baseline' variables are expected to predict the number of selfcitations.

\subsubsection{Past productivity}

The number of publications co-authored in the past increases the pool of articles that can be cited. Hence, a variable measures the cumulative number of publications up to year i-1. At the same time, the journals' editors and reviewers can notice and criticize the inclusion of many self-citations; some publishers even recommend that authors "minimize self-citations" for the sake of preserving anonymity in the peer review process. ${ }^{14}$ Therefore, it is more difficult for an author with a large pool of past publications (e.g. 50) to self-cite a large share of

\footnotetext{
${ }^{9}$ The candidate can choose that the indexes are computed using either the Scopus or Web of Science databases.

${ }^{10}$ First we manually identified the Scopus ID of each scientist affiliated with the four disciplines between 2002 and 2014. In order to check the right association and avoid problems with homonyms, we manually checked whether the following elements matched: 1) the last and first name; 2) ORCID digital identifier, if any; 3) the correct university and departmental affiliation name (controlling for changes over time). Next, we collected the scientific products and the associated citation overview of each ID by using an automatic approach.

${ }^{11}$ Cineca is a non-profit consortium of Italian universities, national research centres, and the Ministry of Universities and Research (MIUR), which is formally in charge of collecting statistics on Italian Higher Education and research system.

${ }^{12}$ Each of the four selected recruitment sectors includes only one disciplinary sector.

${ }^{13}$ (Total number of self-citations made in year i)/(number of articles published in year i).

${ }^{14}$ For instance, see the authors' guidelines from publisher Taylor and Francis, available at: http://www.tandf.co.uk/journals/pdf/Author/anonymous_peer_review.pdf.
} 
their own past publications, than an author with a smaller pool of publications (e.g. five), as it is more acceptable to include, for example, two self-citations rather than twenty self-citations. Hence, we introduce a variable given by the square of the cumulative number of publications up to year i- 1 in order to consider the expected decreasing marginal effect of an additional item in the pool of past publications.

\subsubsection{Number of co-authors}

One variable measures the average number of co-authors for a scientist's publications in year i. It can be expected that the larger the number of co-authors in a publication, the lower the number of selfcitations that can be included for each of them. In fact, an article is unlikely to be equally related to the work of all co-authors; it can be very central to one co-authors' agenda (e.g. the corresponding author) and less central for the others. Hence, some co-authors may find much of their own past work relevant, while others find few. The characteristics of the scientist may also affect the propensity to self-cite.

\subsubsection{Academic rank}

Since self-citations can be used to increase prestige (Hutson, 2006) and scientists with lower academic rankings may have a higher need to affirm their status, meaning it is expected that assistant professors and associate professors will cite their work more frequently than full professors. A dummy variable considers the scientist's academic rank in year i, namely assistant professor (ricercatore), associate professor (professore associato) and full professor (professore ordinario).

\subsubsection{Citation standing}

Scientists that receive many citations may be more confident regarding the relevance and value of their work, and therefore be more prone to citing it. We introduce a variable given by the author's cumulative amount of citations received up to year i normalized by the cumulative citations received up to year $i$ by the median scientist of the same rank and disciplinary group.

\subsubsection{Gender}

Three studies on self-citations explored gender variations and found that male scientists are more prone to self-cite than female scientists (Hutson, 2006; Maliniak et al., 2013; King et al., 2017). We therefore include a dummy variable for a scientist's gender.

\subsubsection{Professional age}

The propensity to cite one's own work increases with the professional age of the author (Hutson, 2006). Possibly, this may reflect the fact that senior academics are less prone to explore new areas of research compared to their younger colleagues.

Additionally, the contextual characteristics of a scientist's work can affect the propensity to self-cite.

\subsubsection{Group research quality}

The level of competition for prestige can be stronger in high quality groups. As a proxy for research quality, we consider the results of the national research assessment exercise (VQR), which considered scientific production from 2004 to 2010. In particular, the average evaluation of the publications of a university in macro-area $y$ normalized by the average evaluation in macro area $y$.

\subsection{Variables predicting the increase of self-citations}

\subsubsection{Habilitation}

We expect the introduction of habilitation criteria considering the number of citations to increase the propensity to self-cite. We construct and separately test dummy variables for the years after the law was issued.

\subsubsection{The moderating effect of academic rank on habilitation}

We test the moderating effect of academic rank on the habilitation process to explore changes in the number of self-citations among assistant and associate professors.

\subsubsection{The moderating effect of the citation standing on habilitation}

We test a moderating effect of the citation standing on the habilitation process to explore whether scientists that are less cited than their peers of the same rank and discipline will increase the number of selfcitations at a higher rate.

\subsubsection{Career prospects}

We controlled for a competing explanation on the increase of selfcitations, namely that scientists increase self-citations to boost the metric scores when they perceive to have concrete prospects for career advancement. As a proxy for the perception of future career prospects, we consider the ratio between new positions created in the next three years, e.g. as associate professors divided by the current number of assistant professors: $:^{15}$

Career prospects $=\left(\right.$ New positions rank $_{x+1}$ year $_{i \rightarrow i+3}$ discipline $\left._{k}\right) /(N$. rank $_{x}$ year $_{i}$ discipline $_{k}$ )

We computed the variable both at the national and university level, assuming that perceptions about future career prospects are affected by dynamics at both levels. The two variables are highly correlated, and a factor analysis extracts a unique factor absorbing $70 \%$ of the variance, which we employ as a variable of "career prospects". We also test the interaction with the Habilitation variable.

\subsection{Analyses}

The empirical analysis combines descriptive and inferential statistics.

First, we describe the longitudinal evolution in scientists' propensity to self-cite along the four disciplines.

Next, we run regression models to test the factors predicting the number of self-citations and the change in self-citation behaviour related to the habilitation process. Since disciplines have distinctive trends in terms of the evolution of self-citations and responses to metrics, we do not pool them in a unique test; instead, we run separate regressions for each discipline as they provide more accurate results. The dependent variable is the yearly number of self-citations per article for each scientist, and it is over dispersed (i.e. the variance increases faster than the mean). For similar dependent variables, negative binomial regressions are preferred to Poisson regressions because they include a distinct parameter to model over dispersion (Snijders and Bosker, 2012). ${ }^{16}$

The data have a three-level structure, with years nested into scientists, nested within universities. We employ a multilevel regression model, which disentanlge the variance due to individual and contextual factors and more accurately computes estimates (Robinson, 2009; Snijders and Bosker, 2012). Multicollinearity is not a major concern in our regression models because the average variance inflation factor is 1.82 , well below the critical cut-off of ten.

To rule out the possibility that changes in the number of self-citations are driven by an overlapping general trend, rather than by the introduction of the habilitation criteria, we adopt a regression discontinuity design (RDD) (Imbens and Lemieux, 2008). The use of a RDD design is motivated by the fact that this quasi-experimental setting uses

\footnotetext{
15 The variable takes value 0 for all full professors.

${ }^{16}$ It is important to remember that binomial regression coefficients are exponential and multiplicative: if the coefficient for an antecedent is $\beta$, then the change in the expected number of counts for a unit change in the antecedent is given by the exponential of $\beta$. For instance: coefficient 0.375 , exponential $(0.375)=1.45$, increase $+45 \%$.
} 
Table 2

Descriptive statistics.

\begin{tabular}{|c|c|c|c|c|c|c|}
\hline \multicolumn{2}{|c|}{ variable } & Min & Median & Mean & Max & $\begin{array}{l}\text { Standard } \\
\text { Deviation }\end{array}$ \\
\hline \multicolumn{2}{|c|}{ Self - citations per article } & 0.00 & 1.00 & 1.42 & 16.18 & 1.72 \\
\hline \multicolumn{2}{|c|}{ Proportion self-citations on references } & 0.00 & 0.02 & 0.03 & 1.00 & 0.05 \\
\hline \multicolumn{2}{|c|}{ Past production (n. publications) } & 0 & 21 & 37 & 433 & 47 \\
\hline \multicolumn{2}{|c|}{ N. co-authors } & 1.00 & 5.50 & 6.09 & 22.00 & 3.72 \\
\hline \multicolumn{2}{|c|}{ Citation standing (normalized) } & 0.00 & 0.70 & 1.23 & 22.90 & 1.67 \\
\hline \multicolumn{2}{|c|}{ Professional age (years) } & 0.00 & 16.00 & 17.74 & 59.00 & 10.79 \\
\hline \multicolumn{2}{|c|}{ Group's Research quality } & 0.00 & 1.03 & 1.04 & 2.83 & 0.26 \\
\hline \multicolumn{2}{|c|}{ Career prospects: national } & 0.00 & 0.07 & 0.10 & 0.88 & 0.12 \\
\hline \multicolumn{2}{|c|}{ Career prospects: university } & 0.00 & 0.00 & 0.08 & 3.00 & 0.21 \\
\hline \multirow[t]{3}{*}{ rank } & assistant professors & & 2.317 & & $40 \%$ & \\
\hline & associate professors & & 1.804 & & $31 \%$ & \\
\hline & full professors & & 1.659 & & $29 \%$ & \\
\hline \multirow[t]{2}{*}{ gender } & Female & & 1.978 & & $34 \%$ & \\
\hline & Male & & 3.802 & & $66 \%$ & \\
\hline
\end{tabular}

Table 3

Pearson correlations.

\begin{tabular}{|c|c|c|c|c|c|c|c|c|c|c|}
\hline & & 1 & 2 & 3 & 4 & 5 & 6 & 7 & 8 & 9 \\
\hline 1 & Self - citations per article & 1 & $0.784^{* * *}$ & $0.290^{* *}$ & $0.150^{* *}$ & $0.104^{* k * k}$ & $0.225^{\text {*** }}$ & $0.258^{* k t}$ & $0.054^{* * *}$ & $-0.087^{* *}$ \\
\hline 2 & Proportion self-citations on references & $0.784^{* * *}$ & 1 & $0.233^{* * *}$ & $0.113^{\text {** }}$ & 0.011 & $0.159^{* * *}$ & $0.247^{k+k}$ & 0.019 & $-0.081^{* *}$ \\
\hline 3 & Past production (n. publications) & $0.290^{\text {k* }}$ & $0.233^{* *}$ & 1 & $0.270^{* *}$ & $0.067^{* * k}$ & $0.365^{k *}$ & $0.478^{* * *}$ & $0.119^{* *}$ & $-0.251^{* *}$ \\
\hline 4 & N. co-authors & $0.150^{\text {k* }}$ & $0.113^{\text {*** }}$ & $0.270^{* *}$ & 1 & $0.035^{* k *}$ & $0.030^{*}$ & $0.300^{* * *}$ & $-0.053^{* * *}$ & $-0.206^{* * *}$ \\
\hline 5 & Habilitation dummy (year 2011) & $0.104^{\text {k* }}$ & 0.011 & $0.067^{* *}$ & $0.035^{* *}$ & 1 & $-0.033^{*}$ & $0.034^{k \text { k*t }}$ & -0.004 & $0.126^{\text {** }}$ \\
\hline 6 & Citation standing (normalized) & $0.225^{* * *}$ & $0.159^{* * *}$ & $0.365^{* * *}$ & $0.030^{*}$ & $-0.033^{k}$ & 1 & $0.130^{\text {tike }}$ & $0.155^{* *}$ & $0.049^{k * *}$ \\
\hline 7 & Professional age (years) - log norm & $0.258^{k * *}$ & $0.247^{* *}$ & $0.478^{* * *}$ & $0.300^{* *}$ & $0.034^{\text {kik }}$ & $0.130^{* *}$ & 1 & $0.046^{* * *}$ & $-0.376^{* *}$ \\
\hline 8 & Group's Research quality & $0.054^{\text {*** }}$ & 0.019 & $0.119^{* * *}$ & $-0.053^{* *}$ & -0.004 & $0.155^{k \text { *⿰冫欠 }}$ & $0.046^{* * k}$ & 1 & 0.018 \\
\hline 9 & Career prospects (Factor scores) & $-0.087^{* * *}$ & $-0.081^{k * k}$ & $-0.251^{* * *}$ & $-0.206^{* *}$ & $0.126^{* * k}$ & $0.049^{* * *}$ & $-0.376^{* k \pi}$ & 0.018 & 1 \\
\hline
\end{tabular}

* Correlation is significant at the 0.05 level (2-tailed).

** Correlation is significant at the 0.01 level (2-tailed).

treated or not, according to a certain threshold in a reference variable. This methodology is particularly suitable for studying the effects of regulatory changes because it isolates the effects of the regulatory shift from the impact of environmental change and other confounding contemporaneous events (Lee and Lemieux, 2010). In our setting, the forcing variable is the introduction of the habilitation procedure. In other words, the groups of treated and control researchers are not seen as homogeneous, but their behaviour is expected to be more similar the closer they are in time to the introduction of the habilitation procedure. Following the habilitation, some researchers had a direct incentive to use self-citations. In this respect, a RDD allows the isolation of differences in the outcomes between pre and post habilitation periods due to the causal effect of the treatment. The RDD implies the specification of models where a p-th order parametric polynomial accounts for the nonlinearity of the relationship between the time trend and the dependent variable. In particular, we control the counter hypotheses of linear, quadratic and/or cubic growth throughout the period by introducing a third order polynomial centred around the years following the event. The use of a higher order polynomial is discouraged in recent studies (Gelman and Imbens, 2014). ${ }^{17}$

Finally, we develop a robustness test using the proportion of selfcitations among the total number of article references $s_{\text {a }}$ published in

\footnotetext{
17 The RDD, with time as a forcing variable, mimics a diff-in-diff approach, with the following advantages: a) the groups of treated and control researchers are not seen as homogeneous, but the more similar the more they are close (in time) to the introduction of the habilitation procedure; b) the inclusion of a p-th order parametric polynomial accounts for non-linearity of the relationship between the time trend and the dependent variable.
}

the proportion of self-citations for each year-scientist:

$P_{i, j}=\frac{\sum_{a=1}^{A} \text { self }- \text { citations }_{a, i, j}}{\sum_{a=1}^{A} \text { references }_{a, i, j}}$

\section{Empirical analysis}

\subsection{Descriptive statistics}

Table 2 displays the descriptive statistics of the selected variables.

The correlations are mostly significant but low, with the exception of the correlation between the two dependent variables (0.784) (Table 3). The correlation of the dependent variables with the mean number of co-authors is positive, yet correlations run per each discipline are negative or null.

Fig. 1 illustrates the evolution in the number of self-citations per article between 2002 and 2014 for the four disciplines, for assistant and associate professors. As to the left side, self-citations have grown in Applied Economics, however more irregularly and less strongly than in Economic and Managerial Engineering, where citations have remarkably grown after the introduction of the habilitation procedure in late 2010. As to the right side, the growth of self-citations appear to have also accelerated after 2010 in Psychiatry - especially for associate professors - as well as in Genetics, although a spike in self-citations occurred in 2009. 


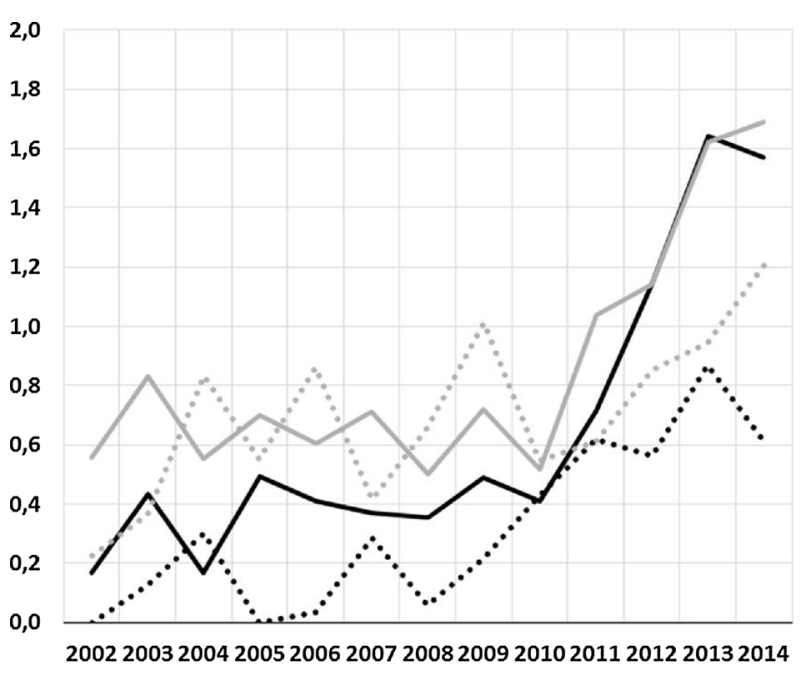

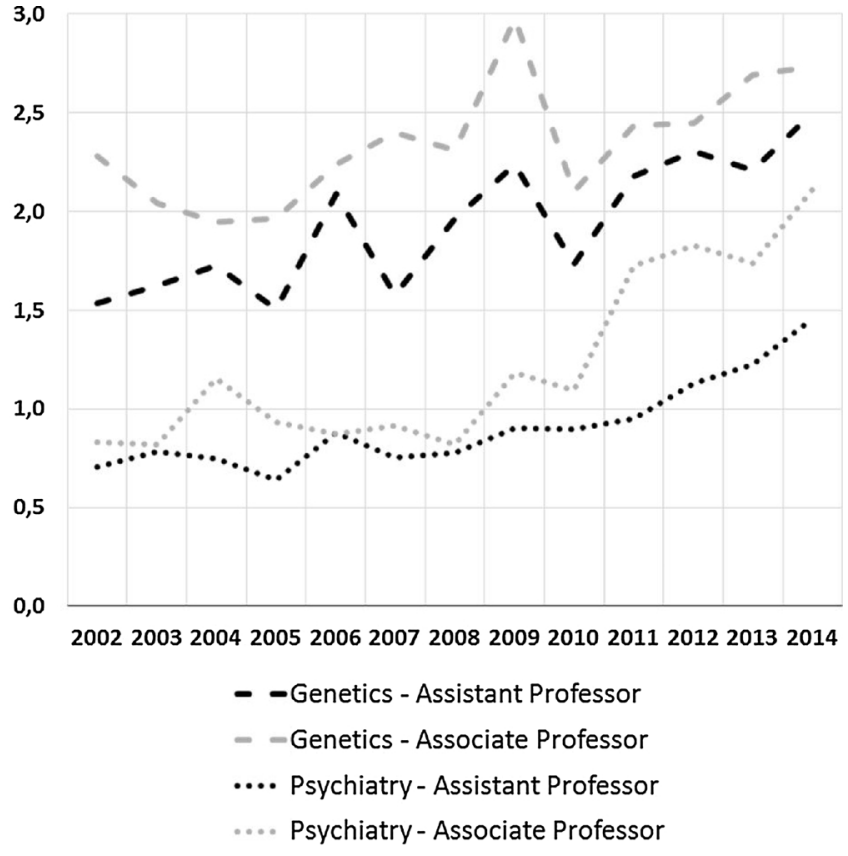

Fig. 1. Evolution of the number of self-citations per article.

\subsection{Regression analysis}

For each discipline, Table 4 presents the results of two multilevel regression models. The model Habilitation explores the impact of the habilitation procedure on self-citations by controlling for several predictors. The model Interactions explores the moderation effects of the academic rank and the citation standing.

We tested alternative specifications of the habilitation variable with years 2011, 2012 and 2013 to identify whether and when a significant increase was observed after the issuing of the law setting the habilitation procedure. ${ }^{18}$ A significant increase in self-citations for the selected groups of scientists is observed from 2011 in Economic and Managerial Engineering and in Psychiatry, and from 2012 in Genetics. Such time intervals are consistent with the time usually needed from submission to publication in these fields, which is on average 20 weeks in Psychology, 25 in Economics and Business and longer in Genetics: 35 weeks (Huisman and Smits, 2017; Kareiva et al., 2002). This finding suggests that scientists have been strongly reactive in changing their self-citation practices ever since the law was issued.

The results show that in Economic and Managerial Engineering, a social science discipline that adopts a bibliometric approach, the habilitation had a strong and significant effect in increasing self-citations, even at the field level. The estimated effect of the habilitation from 2011 to 2014 is to increase self-citations by $81 \%(+0.60$ self-citations per article). ${ }^{19}$ The results of the model Interactions show that the habilitation procedure has been responsible for a significant growth in self-citations for assistant $(+0.85$ self-citations, $+179 \%)$ associate $(+0.63,+91 \%)$ and even full professors $(+0.55,+43 \%)$, as well as for scientists that are relatively less cited then their peers.

In Psychiatry and Genetics, disciplines in the Natural Science and Medicine that adopt a bibliometric approach, the habilitation had a positive but not a significant effect in increasing self-citations when the fields as a whole are considered. On the other side, the moderation terms have a strong and significant effect for assistant professors

\footnotetext{
${ }^{18}$ Results are available upon request.

19 The exponential of the regression coefficient ( 0.375$)$ means $+45 \%$ in comparison to a hypothetical self-citation rate in 2014 without the habilitation.
}

$(+1.88,+73 \%)$ and associate professors $(+1.24,+61 \%)$ in Psychiatry and for assistant professors in Genetics $(+0.75,+33 \%),{ }^{20}$ and in both disciplines for scientists that are relatively less cited.

Finally, no significant increase is observed in Applied Economics - a social science discipline that adopts the non-bibliometric approach either at the field level or among the interaction terms with academic rank and citation standings.

In sum, Hypotheses 1 and Hypotheses 2 are supported to a large extent by the results of the regressions, as scientists that need to climb the career ladder - i.e. assistant and associate professors - and those that are relatively less cited than their peers have responded to the use of citations to guide career decisions by increasing the number of selfcitations. Hypotheses 3 is also supported by the results, given that the strongest increase in self-citations - both in the discipline as a whole and for each academic rank separately - is observed in social sciences discipline that adopt a bibliometric approach. Table 5 resumes the expected and observed increase in self-citations.

As to the other predictors, an important remark is that the gender variable is not significant. While previous studies that observed gender differences in self-citation propensity included a limited number of covariates (Hutson, 2006; Maliniak et al., 2013; King et al., 2017), this result suggests that differences disappear if several covariates are considered. The professional age is only a significant predictor in Applied Economics, whereas the group's research quality is never significant. Associate and assistant professors tend to self-cite more than full professors, with the exception of Genetics. Scientists receiving many citations self-cite their own work more, except for Applied Economics.

\subsection{Robustness test}

For the robustness test, we run the 'Habilitation' and 'Interactions' models for each discipline by employing the ratio between the total number of self-citations and the total number of references in the articles published by a given scientists in year i (Table 6) as the dependent

\footnotetext{
${ }^{20}$ In Genetics the growth of self-citations for Associate Professors is significant when considering the proportion of self-citations on total references - see robustness test (Table 6).
} 


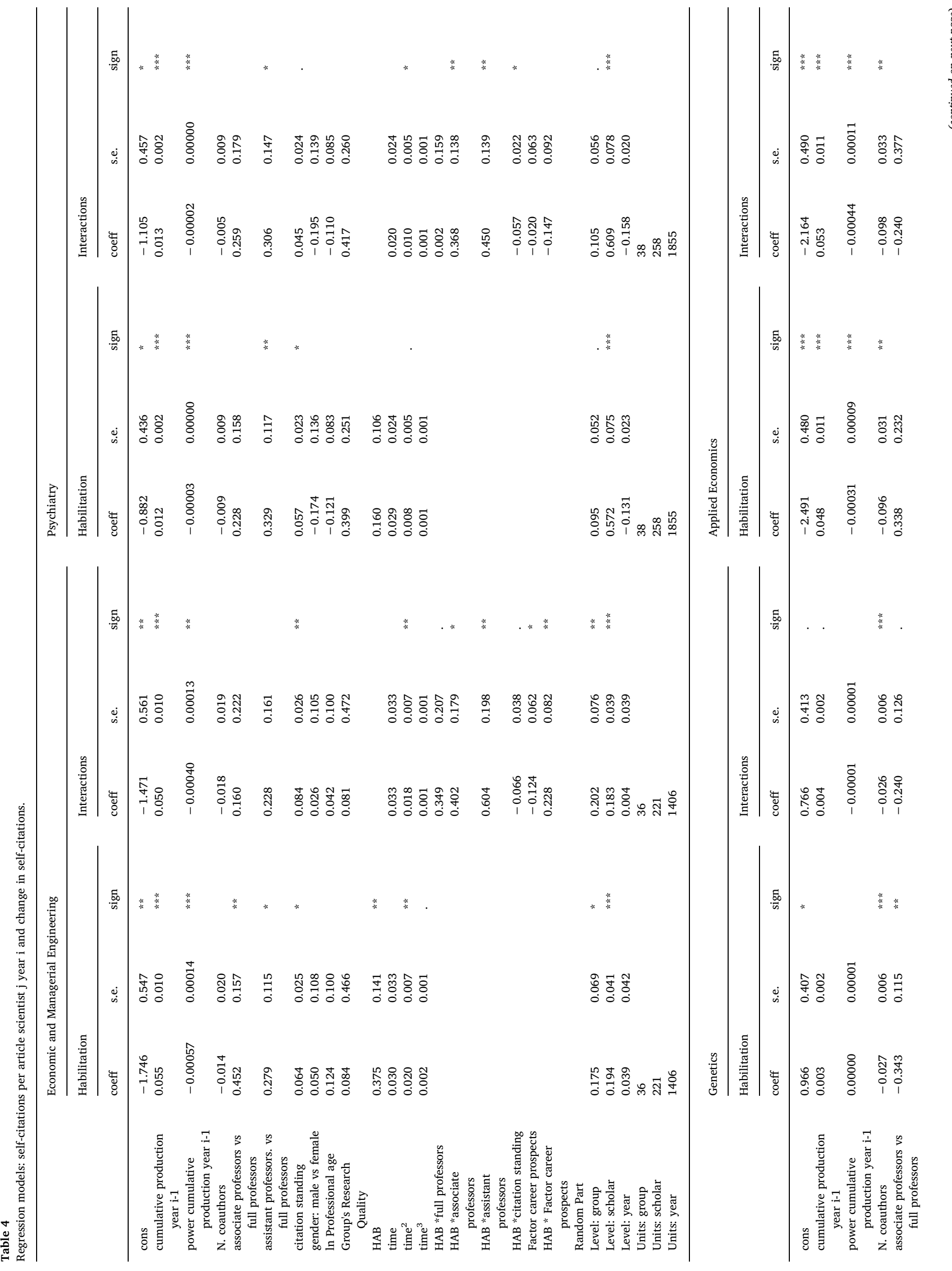




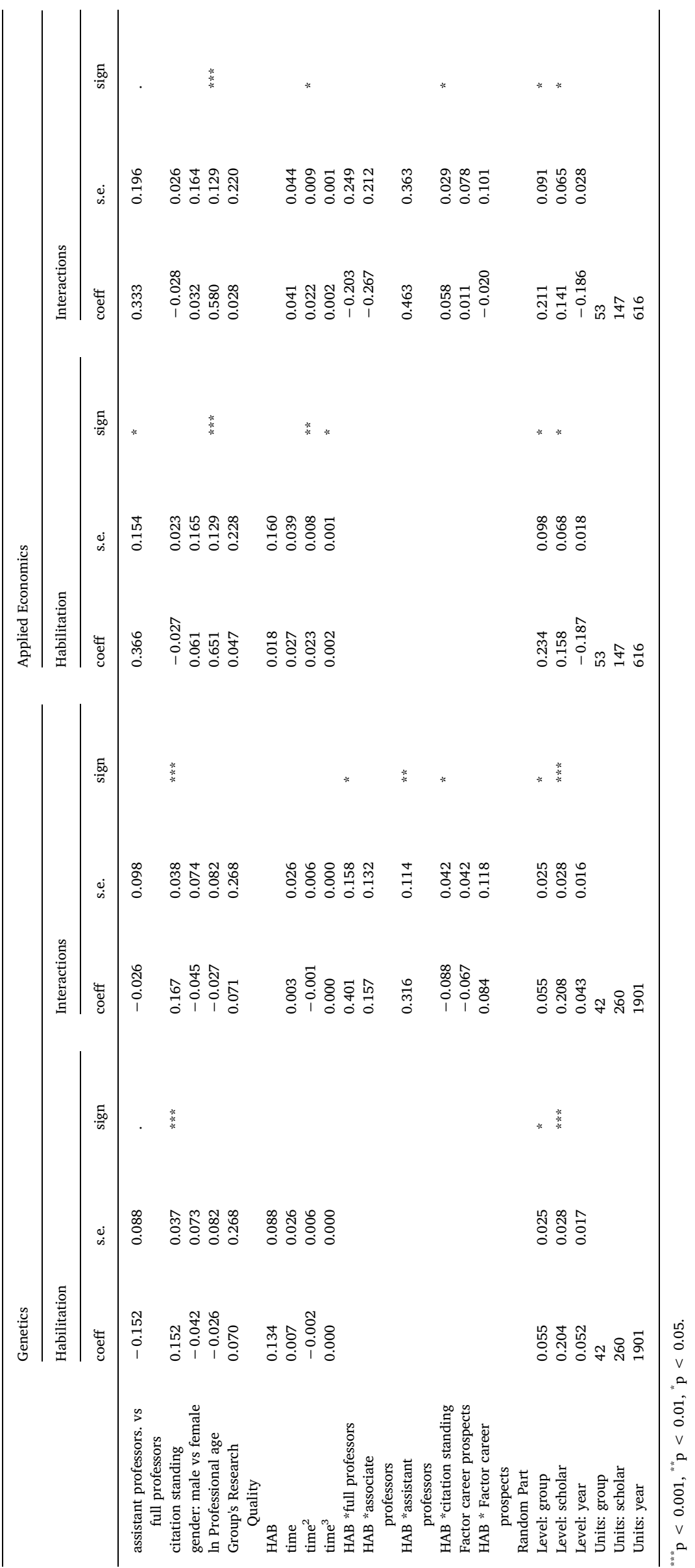


Table 5

Comparisons between predicted growth in self-citations and observed growth.

\begin{tabular}{|c|c|c|c|c|c|c|c|c|c|c|}
\hline \multirow[t]{2}{*}{ Recruitment Sector } & \multirow[t]{2}{*}{ Metric approach } & \multirow[t]{2}{*}{ Scientific Area } & \multicolumn{2}{|c|}{ associate professors (hp 1) } & \multicolumn{2}{|c|}{ assistant professors (hp 1) } & \multicolumn{2}{|c|}{ under cited scientists (hp 2) } & \multicolumn{2}{|c|}{ disciplines (hp 3) } \\
\hline & & & predicted & observed & pred. & obs. & pred. & obs. & pred. & obs. \\
\hline $\begin{array}{l}\text { Managerial } \\
\text { Engineering }\end{array}$ & Bibliometric & Social Science & yes & yes & yes & yes & yes & yes & strong & strong \\
\hline Psychiatry & Bibliometric & Medicine & yes & yes & yes & yes & yes & yes & less strong & less strong \\
\hline Genetics & Bibliometric & $\begin{array}{l}\text { Natural } \\
\text { Science }\end{array}$ & yes & $\mathrm{no}^{\mathrm{a}}$ & yes & yes & yes & yes & less strong & less strong \\
\hline Applied Economics & Non-bibliometric & Social Science & no & no & no & no & no & no & no & no \\
\hline
\end{tabular}

${ }^{\mathrm{a}}$ Growth is significant when considering the proportion of self-citations - see robustness test (Table 6).

variable. The results are very similar to the results of the test that used the average number of self-citations per article as a dependent variable. The main difference pertains to assistant professors in Genetics, whose self-citations also increased significantly.

\subsection{Impact of self-citations}

Fig. 2 illustrates the relative weight of the self-citations compared to the habilitation threshold in the three bibliometric disciplines, for the pool of assistant and associate professors. While the contribution in Psychiatry and Genetics is rather small, self-citations alone provide a substantial contribution in Economic and Managerial Engineering, and have increased quickly and strongly after the habilitation procedure was introduced. In turn, self-citations allow more scientists to meet the habilitation thresholds in Economic and Managerial Engineering $(+18 \%$ for assistant professors and $+9 \%$ for associate professors, year 2014), in Genetics $(+5 \%$ and $+4 \%)$, and in Psychiatry $(+8 \%$ for assistant professors).

\section{Discussion and conclusions}

This article explored whether scientists respond to the use of citations as a formal criterion to drive career decisions by opportunistically increasing self-citations. We focused in particular on the use of selfcitations, as they can be exploited in a rather short period of time and be easily detected, thus representing a precious 'canary in a coal mine'. The Italian Higher Education system was considered as a forerunner in the adoption of a national habilitation procedure based on the number of publications and citations received.

The empirical analysis shows that scientists respond to the use of citations to guide decisions on academic careers by increasing self-citations, in particular scientists that are more likely to benefit, namely assistant and associate professors and professors with fewer citations when compared to their peers, especially social scientists.

Some choices and assumptions should be discussed. First, some observers may regard the inflation of self-citations as a minor infringement. However, self-citations have an important impact on visibility, each self-citation generating 3.65 additional citations (Fowler and Aksnes, 2007) and inflating self-citations is a post-production malpractice that may undermine trust in the publication system (Biagioli, 2016), as well as erode confidence in the self-policing capabilities of the academic community. Second, we assume that a rapid increase in self-citations corresponding to the introduction of the habilitation procedure is likely indicative of a strategic use of self-citations, rather than publications becoming more similar in their focus.
Future studies may try to disentangle the two effects. Third, we considered only one national system. This choice was driven by the fact that Italy represents a valuable case as a forerunner in adopting a system-wide, metric-based procedure for guiding career decisions.

The findings have implications on the theoretical understanding of scientists' behaviour. Scientists were found to be very responsive to incentives, as self-citations increased soon after the law on habilitation was issued, and scientists were keen to adopt a questionable practice that is beneficial and not sanctioned.

Relevant variations emerge between disciplines among the factors that predict the propensity to self-cite. Moreover, a multilevel perspective highlights that the variability in self-citing behaviour also related to the university of belonging, suggesting the importance of organizational norms and habits.

Policy implications emerge in relation to the increasingly wide, pervasive and formalized use of metrics. Indicators of productivity may be valuable in assisting evaluation, and they can be helpful to increase accountability in contexts characterized by a lack of meritocracy. However, this study suggests that - while metrics are adopted to spur virtuous behaviours - if not properly designed they favour the diffusion of questionable practices instead. Therefore, metrics designers should carefully take into account the strategic nature of scientists. First, selfcitations should not be considered. Second, the value of a citation could be proportional to the distance (institutional or in the network of authorships) between the citing and cited authors, as a greater distance between the authors reduces the risk of collusion. Alternatively, additional citations from the same author would hold a reduced value, e.g. "one divided by the number of citations already given". Third, beyond the number of citations received, also the number of citing documents and citing authors could be taken into consideration for evaluation purposes.

In conclusion, this article focused on the use of self-citations, as they can be easily measured and provide fast benefits. Yet the more academic rewards become connected to metrics - rather than discovery achievement - the more research and publication strategies are likely to become intertwined. Accordingly, two further responses from scientists can be foreseen in the mid and long term. First, metrics can affect the balance between exploration and exploitation in scientists' research strategies, e.g. towards more specialization and/or small incremental changes from one publication to another. Second, scientists may be abandoning themes and types of research that are less cited, such as theoretical ones, which are cited less than applied ones (Anauati et al., 2016). Future research should monitor the existence of similar responses, which would have a direct impact on the production of knowledge. 


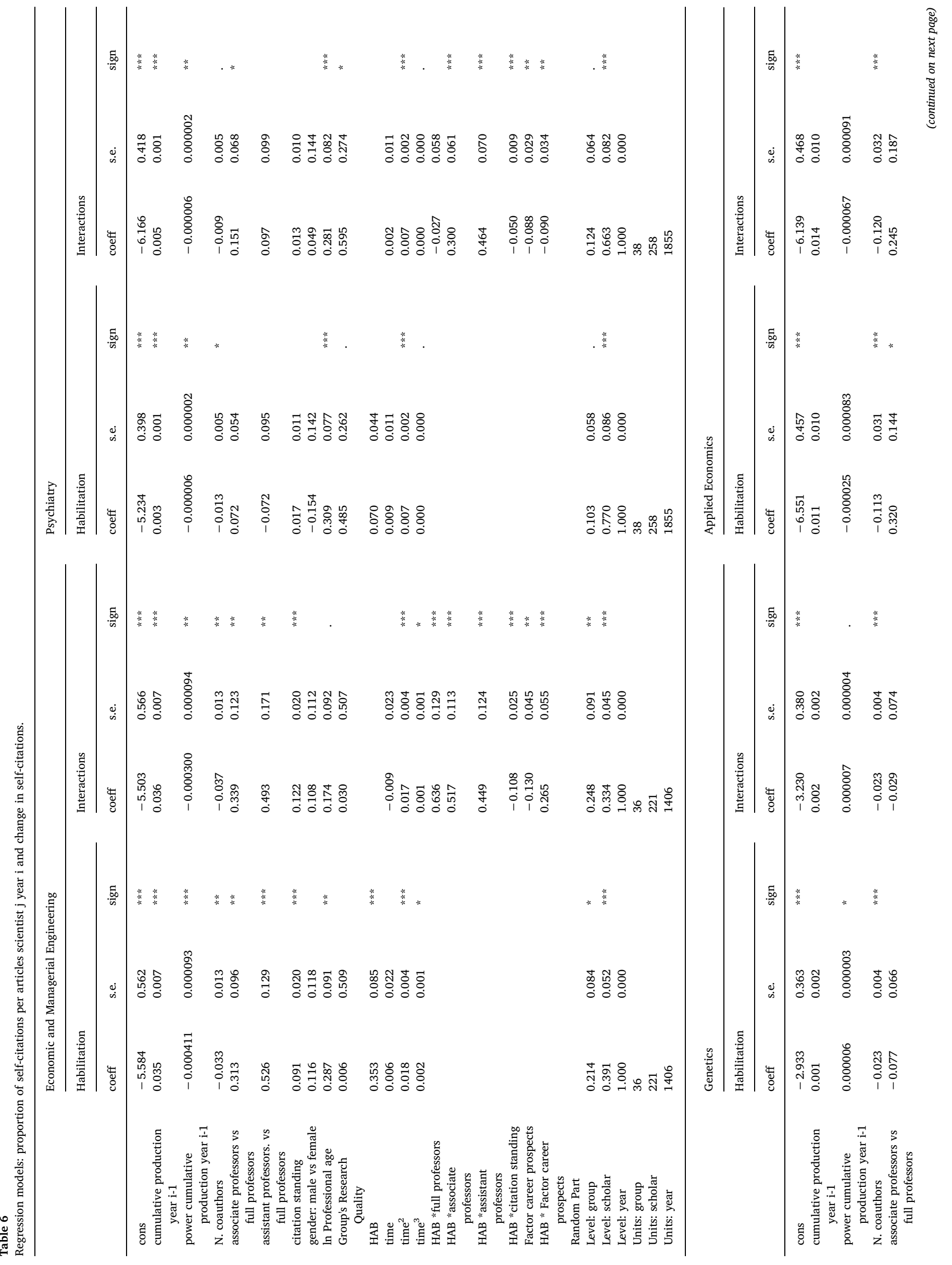




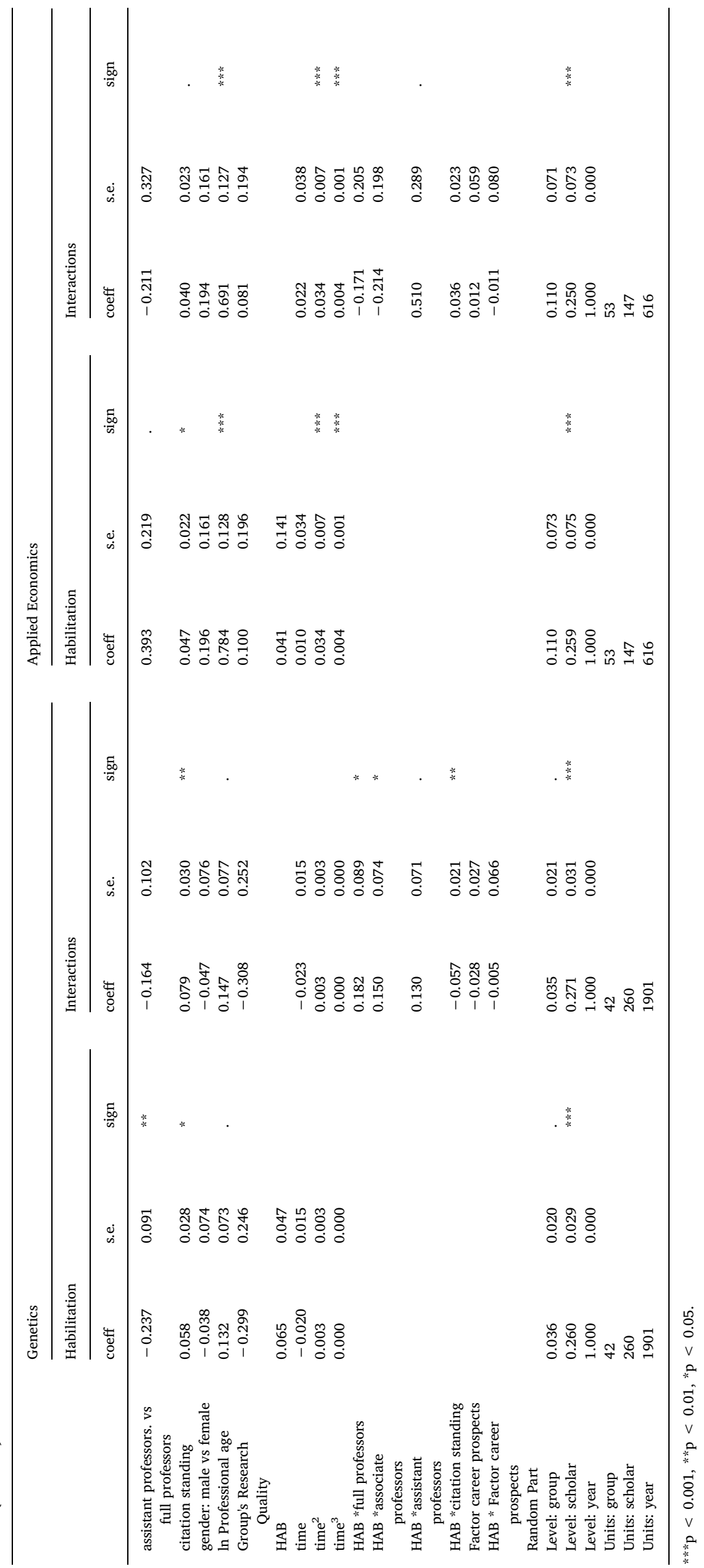




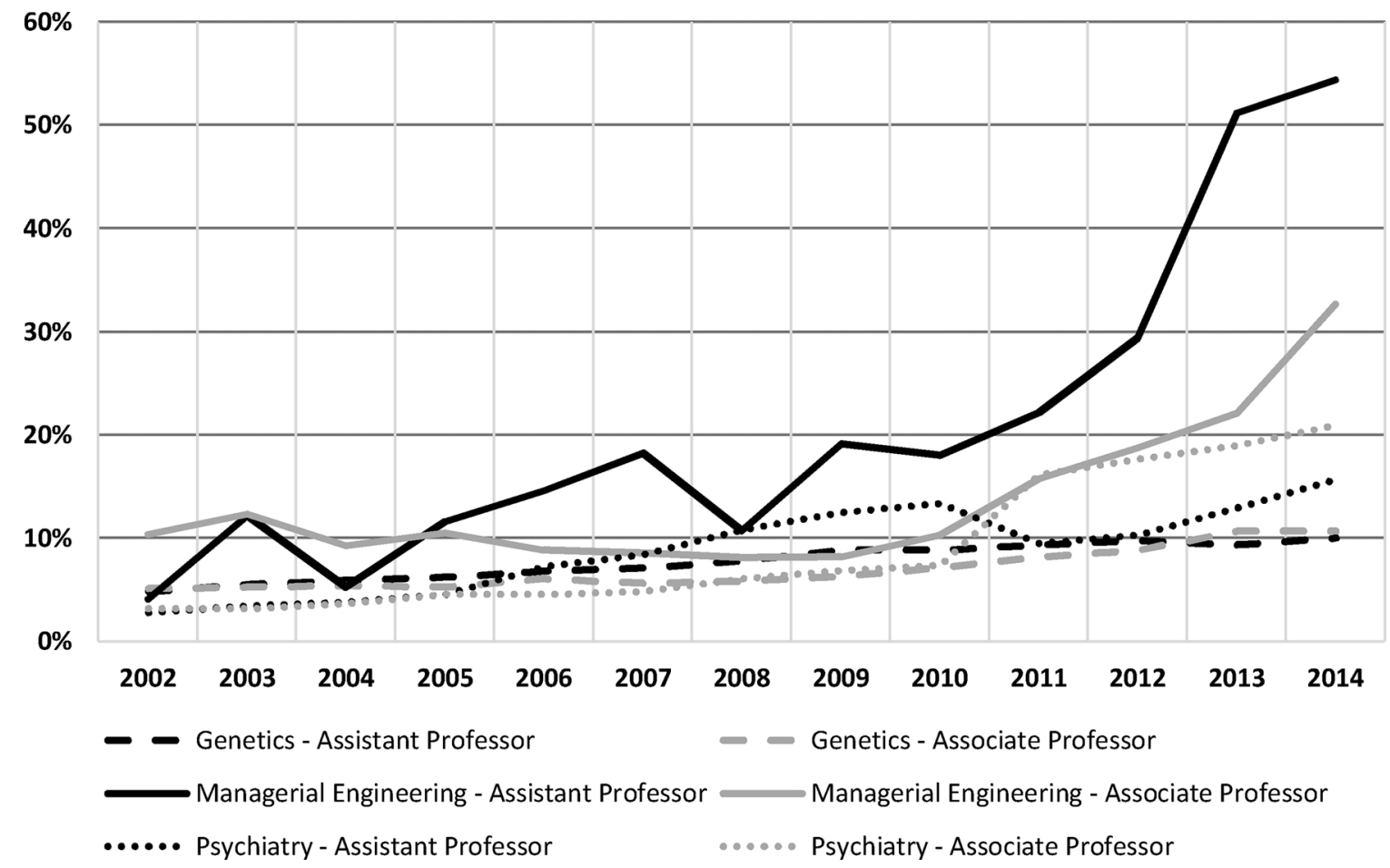

Fig. 2. The contribution of self-citations to habilitation thresholds. Avg Ratio rank $x$ discipline $k$

$=\underline{(\text { Cumulative selfcitations scientists } \mathrm{j} \text { up to year } \mathrm{i}) /(\mathrm{n} \text { years from first publication) }}$ habilitation threshold

\section{Acknowledgments}

We thank the two reviewers for their insightful comments, Hugo Horta and Jeroen Huisman for their comments on a draft version of the article, Andrea Bonaccorsi and Cinzia Daraio for their exchange of ideas. We also thank Kelvyn Jones for discussing the statistical method, Michele Seeber for his support in data retrieval, and Michael Wise for carefully proofreading the manuscript. This work was supported by Fonds Voor Wetenschappelijk Onderzoek Vlaanderen - [grant number G.OC42.13N].

\section{References}

Aagaard, K., Bloch, C., Schneider, J.W., 2015. Impacts of performance-based research funding systems: the case of the Norwegian Publication Indicator. Res. Eval. 24 (2), 106-117.

Aksnes, D.W., Rip, A., 2009. Researchers' perceptions of citations. Res. Policy 38 (6), 895-905.

Aksnes, D.W., 2006. Citation rates and perceptions of scientific contribution. J. Am. Soc. Inf. Sci. Technol. 57 (2), 169-185.

Anauati, V., Galiani, S., Gálvez, R.H., 2016. Quantifying the life cycle of scholarly articles across fields of economic research. Econ. Inq. 54 (2), 1339-1355.

Anderson, M.S., Louis, K.S., Jason, E., 1994. Disciplinary and departmental effects on observations of faculty and graduate student misconduct. J. Higher Educ. 65 (3), 331-350.

Anderson, M.S., Ronning, E.A., De Vries, R., Martinson, B.C., 2007. The perverse effects of competition on scientists' work and relationships. Sci. Eng. Ethics 13 (4), 437-461.

Auranen, O., Nieminen, M., 2010. University research funding and publication performance-an international comparison. Res. Policy 39 (6), 822-834.

Azoulay, P., Graff Zivin, J.S., Manso, G., 2011. Incentives and creativity: evidence from the academic life sciences. Rand J. Econ. 42 (3), 527-554.

Bedeian, A.G., Taylor, S.G., Miller, A.N., 2010. Management science on the credibility bubble: cardinal sins and various misdemeanors. Acad. Manage. Learn. Educ. 9 (4), 715-725.

Biagioli, M., 2016. Watch out for cheats in citation game. Nature 535 (7611) 201-201.

Bornmann, L., Daniel, H.D., 2007. Multiple publication on a single research study: does it pay? The influence of number of research articles on total citation counts in biomedicine. J. Am. Soc. Inf. Sci. Technol. 58 (8), 1100-1107.

Bush, V., 1945. Science: the endless frontier. Trans. Kansas Acad. Sci. (1903-) 48 (3), 231-264.
Clark, B., 1983. The Higher Education System. Academic Organization in Cross-National Perspective. University of California Press, Berkeley and Los Angeles.

Cole, J.R., Cole, S., 1974. Social stratification in science. Am. J. Phys. 42 (10), 923-924.

Costas, R., Bordons, M., 2007. The h-index: advantages, limitations and its relation with other bibliometric indicators at the micro level. Hirsch Index 1 (3), 193-203.

de Rijcke, S., Wouters, P.F., Rushforth, A.D., Franssen, T.P., Hammarfelt, B., 2016. Evaluation practices and effects of indicator use-a literature review. Res. Eval. 25 (2), 161-169.

De Rond, M., Miller, A.N., 2005. Publish or perish: bane or boon of academic life? J. Manage. Inquiry 14 (4), 321-329.

Donina, D., Meoli, M., Paleari, S., 2015. Higher education reform in Italy: tightening regulation instead of steering at a distance. Higher Educ. Policy 28 (2), 215-234.

Durante, R., Labartino, G., Perotti, R., 2011. Academic Dynasties: Decentralization and Familism in the Italian Academia (No. w17572). National Bureau of Economic Research.

ETER, 2014. European Tertiary Education Register. available at: https://www.eterproject.com/.

Edwards, M.A., Roy, S., 2017. Academic research in the 21st century: maintaining scientific integrity in a climate of perverse incentives and hypercompetition. Environ. Eng. Sci. 34 (1), 51-61.

Eiduson, B.T., 1962. Scientists: Their Psychological World.

Fanelli, D., 2012. Negative results are disappearing from most disciplines and countries. Scientometrics 90 (3), 891-904.

Fang, F.C., Steen, R.G., Casadevall, A., 2012. Misconduct accounts for the majority of retracted scientific publications. Proc. Natl. Acad. Sci. 109 (42), 17028-17033.

Fowler, J.H., Aksnes, D.W., 2007. Does self-citation pay? Scientometrics 72 (3), 427-437.

Franzoni, C., Scellato, G., Stephan, P., 2011. Changing incentives to publish. Science 333, 702-703.

Garfield, E., 2003. The meaning of the impact factor. Int. J. Clin. Health Psychol. 3 (2), 363-369.

Gelman, A., Imbens, G., 2014. Why High-order Polynomials Should Not Be Used in Regression Discontinuity Designs (No. 20405). National Bureau of Economic Research, Cambridge, MA three variables centred in the year of event.

Hackett, E.J., 1994. A social control perspective on scientific misconduct. J. High. Educ. $242-260$.

Hagstrom, W.O., 1965. The Scientific Community (Vol. 304). Basic Books, New York.

Hagstrom, W.O., 1974. Competition in science. Am. Sociol. Rev. 1-18.

Hammarfelt, B., de Rijcke, S., 2015. Accountability in context: effects of research evaluation systems on publication practices, disciplinary norms, and individual working routines in the faculty of Arts at Uppsala University. Res. Eval. 24 (1), 63-77.

Harzing, A.W., 2010. The Publish or Perish Book. Tarma Software Research, Melbourne.

Haustein, S., Larivière, V., 2015. The use of bibliometrics for assessing research: possibilities, limitations and adverse effects. Incentives and Performance. Springer International Publishing, pp. 121-139. 
Heinze, T., Shapira, P., Rogers, J.D., Senker, J.M., 2009. Organizational and institutional influences on creativity in scientific research. Res. Policy 38 (4), 610-623.

Hirsch, J.E., 2005. An index to quantify an individual's scientific research output. Proc Natl. Acad. Sci. U. S. A. 16569-16572.

Honig, B., Bedi, A., 2012. The fox in the hen house: a critical examination of plagiarism among members of the academy of management. Acad. Manage. Learn. Educ. 11 (1), $101-123$.

Huisman, J., Smits, J., 2017. Duration and quality of the peer review process: the author's perspective. Scientometrics 1-18.

Hutson, S.R., 2006. Self-citation in archaeology: age, gender, prestige, and the self. J. Archaeol. Method Theory 13 (1), 1-18.

Imbens, G.W., Lemieux, T., 2008. Regression discontinuity designs: a guide to practice. J. Econometrics 142 (2), 615-635.

Jefferson, T., 1998. Redundant publication in biomedical sciences: scientific misconduct or necessity? Sci. Eng. Ethics 4, 135-140.

Kareiva, P., Marvier, M., West, S., Hornisher, J., 2002. Slow-moving journals hinder conservation efforts. Nature 420, 15.

Keizer, K., Lindenberg, S., Steg, L., 2008. The spreading of disorder. Science 322 (5908), 1681-1685.

King, M.M., Bergstrom, C.T., Correll, S.J., Jacquet, J., West, J.D., 2017. Men set their own cites high: gender and self-citation across fields and over time. Socius 3, 1-22.

Leahey, E., 2007. Not by productivity alone: how visibility and specialization contribute to academic earnings. Am. Sociol. Rev. 72 (4), 533-561.

Lee, D.S., Lemieux, T., 2010. Regression discontinuity designs in economics. J. Econ. Lit. 48 (2), 281-355.

Levin, S.G., Stephan, P.E., 1991. Research productivity over the life cycle: evidence for academic scientists. Am. Econ. Rev. 114-132.

Lissoni, F., Mairesse, J., Montobbio, F., Pezzoni, M., 2011. Scientific productivity and academic promotion: a study on French and Italian physicists. Ind. Corp. Change 20 (1), 253-294.

Lozano, G.A., Larivière, V., Gingras, Y., 2012. The weakening relationship between the impact factor and papers' citations in the digital age. J. Am. Soc. Inf. Sci. Technol. 63 (11), 2140-2145.

MacRoberts, M.H., MacRoberts, B.R., 1989. Problems of citation analysis: a critical review. J. Am. Soc. Inf. Sci. 40 (5), 342.

Maliniak, D., Powers, R., Walter, B.F., 2013. The gender citation gap in international relations. Int. Organ. 67 (04), 889-922.

Marini, G., 2016. New promotion patterns in Italian universities: less seniority and more productivity? Data from ASN. Higher Educ. 1-17.

Martin, B.R., 2013. Whither research integrity? Plagiarism, self-plagiarism and coercive citation in an age of research assessment. Res. Policy 42 (5), 1005-1014.

Martinson, B.C., Anderson, M.S., de Vries, R., 2005. Scientists behaving badly. Nature 435, 737-738.

Merton, R.K., 1973. The normative structure of science. The Sociology of Science: Theoretical and Empirical Investigations. University of Chicago Press.

Merton, R.K., 1988. The Matthew effect in science, II. Cumulative advantage and the symbolism of intellectual property. ISIS 79 (4), 606-623.

Miller, C.C., Glick, W.H., Cardinal, L.B., 2005. The allocation of prestigious positions in organizational science: accumulative advantage, sponsored mobility, and contest mobility. J. Organ. Behav. 26 (5), 489-516.

Miller, D., 2007. Paradigm prison, or in praise of atheoretic research. Strategic Organ. 5 (2), 177-184.

Moed, H.F., 2005. Citation analysis of scientific journals and journal impact measures. Curr. Sci. 89 (12).

Monteleone, S., Torrisi, B., 2012. Geographical analysis of the academic brain drain in Italy. Scientometrics 93 (2), 413-430.

Morano Foadi, S., 2006. Key issues and causes of the Italian brain drain. Innovation 19 (2), 209-222.

Pezzoni, M., Sterzi, V., Lissoni, F., 2012. Career progress in centralized academic systems: social capital and institutions in France and Italy. Res. Policy 41 (4), 704-719 3.

Reale, E., Seeber, M., 2011. Organisation response to institutional pressures in Higher Education: the important role of the disciplines. Higher Educ. 61 (1), 1-22.

Robinson, W.S., 2009. Ecological correlations and the behavior of individuals. Int. J. Epidemiol. 38 (2), 337-341.

Saha, S., Saint, S., Christakis, D.A., 2003. Impact factor: a valid measure of journal quality? JMLA 42-46.

Snijders, T.B., Bosker, R.R., 2012. Multilevel Analysis: An Introduction to Basic and Advanced Multilevel Modeling, second edition. Sage Publishers, London etc.

Steen, R.G., 2010. Retractions in the scientific literature: is the incidence of research fraud increasing? J. Med. Ethics jme-2010.

Stephan, P.E., 1996. The economics of science. J. Econ. Lit. 34 (3), 1199-1235.

Stephan, P., 2012. Perverse incentives. Nature 484 (7392), 29-31.

Van Dalen, H.P., Klamer, A., 2005. Is science a case of wasteful competition? Kyklos 58 (3), 395-414.

Van Fleet, D.D., McWilliams, A., Siegel, D.S., 2000. A theoretical and empirical analysis of journal rankings: the case of formal lists. J. Manage. 26 (5), 839-861.

Whitley, R., 2007. Changing governance of the public sciences. In: Whitley, R., Gläser, J. (Eds.), The Changing Governance of the Sciences. Sociology of the Sciences Yearbook. Springer, Dordrecht, pp. 3-27.

Wilson, J.Q., Kelling, G.L., 1982. Broken windows. Critical Issues in Policing: Contemporary Readings. pp. 395-407.

Wouters, P., et al., 2015. The Metric Tide: Literature Review (Supplementary Report I to the Independent Review of the Role of Metrics in Research Assessment and Management). HEFCE.

Xia, J., Harmon, J.L., Connolly, K.G., Donnelly, R.M., Anderson, M.R., Howard, H.A., 2015. Who publishes in 'predatory' journals? J. Assoc. Inf. Sci. Technol. 66 (7), $1406-1417$.

Zuckerman, H., 1977. Scientific Elite: Nobel Laureates in the United States. Transaction Publishers.

Zuckerman, H., 1987. Citation analysis and the complex problem of intellectual influence. Scientometrics 12, 329-338. 